\title{
KREATIVITAS KAHARUDDIN DEA IMOK DALAM KARYA TARI KEMANG PASIKI KECAMATAN ALAS KABUPATEN SUMBAWA
}

\author{
Eka Nurhayati \\ Institut Seni Indonesia (ISI) Surakarta \\ Jalan Ki Hadjar Dewantara No.19, Kentingan, Jebres, Surakarta 57126 \\ Silvester Pamardi \\ Institut Seni Indonesia (ISI) Surakarta
}

\begin{abstract}
The Kemang Pasiki Dance was created in 2016 by Kaharuddin Dea Imok, who originated from his interest in seeing the skills of Sumbawa women. The problem is formulated in this research the first how to form Kemang Pasiki dance second how to creativity Kaharuddin Dea Imok in creating the Kemang Pasiki dance. Based on the object examined, this research uses a qualitative method describing the research object according to the data in the field in the form of real data. To know about the form of dance Kemang Pasiki researchers use the concept of Suzanne $K$, the writer that is made clear by the opinions of Soedarsono discussing about dance elements that include motion, floor patterns, music, fashion makeup and place Show. Next to discuss about the creativity of Kaharuddin Dea Imok use the thought concept of Mel Rodes, and for the process used $4 P$ namely pribadi (person), pendorong (press), Proses (prosess) and produk (product). The results of the study gained that creativity Kaharuddin Dea Imok can be seen from the experience as a choreographer in creating dance works. Kemang Pasiki Dance forms can be seen Composition of the elements of the movement, the floor pattern, and the Music, fashion makeup and a place of performances that become one unit In the Kemang Pasiki dance performance. Creativity Imok can be seen from the development of the basic movements of Sumbawa dance, and movements that are calculated with the Rdat motion and the Zapin motion and the skills movement of Sumbawa women.
\end{abstract}

Keyword: Kemang Pasiki dance, dance form, and creativity.

\section{PENDAHULUAN}

Tari Kemang Pasiki merupakan tarian daerah Alas Kecamatan Kabupaten Sumbeawa. Tari ini merupakan tari kreasi baru yang mengungkapkan kelembutan dan keterampilan perempuan Sumbawa dalam melakukan aktivitas seharihari. Tari Kemang Pasiki biasanya dipentaskan dalam acara pernikahan, penyambutan tamu, khitanan, dan acara yang berada di Sumbawa lainnya. Tari Kemang Pasiki mempunyai arti yaitu kemang "bunga" yang diartikan sebagai kecantikan dan pasiki "kecerdasan", dari kedua kata tersebut kita bisa mengartikan tentang bagaimana kecantikan, kelembutan, dan kecerdasan yang dimiliki oleh perempian 
Sumbawa pada saat melakukan aktivitas sehari-hari sebagai seorang perempuan (Kaharuddin Dea Imok, wawancara 14 Februari 2018).

Tari Kemang Pasiki diciptakan tahun 2016 oleh salah satu seniman yang bernama Kaharuddin Dea Imok. Kaharuddin merupakan seniman yang berprofesi sebagai guru kesenian di SMAN 1 Alas. Kaharuddin menciptakan tari Kemang Pasiki dengan tuuan untuk melestarikan kesenian Sumbawa khususnya dalam bidang tari. Salah satu bentuk pelestarian kesenian Sumbawa yang dilakukan oleh Kaharuddin Dea Imok yaitu dengan cara menambah repertoar yang berangkat dari tradisi yang ada seperti gerak ataupun musik tradisional Sumbawa yaitu Gong Genang. Penggunaan gerak maupun musik kedalam tari Kemang Pasiki agar memberikan suasana yang lebih hidup dengan menggunakan permaianan nada yang beragam.

Pemerintah Sumbawa mempercayai Kaharuddin Dea Imok dalam mengembangkan tarian kreasi Sumbawa. Terbukti dengan banyaknya tarian yang diciptakan oleh Kaharuddin Dea Imok salah satunya tari Kemang Pasiki. Ada 8 karya yang diciptakan oleh Kaharuddin Dea Imok antara lain, tari Sentek Kemang tahun (2002), tari Lisu tahun (2008), tari Kemang Komal tahun (2009), tari Kemang Tekar tahun (2010), tari Ngumang Malewa versi SMA (2016), tari Kemang Pasiki tahun (2016), tari Ketong Parai tahun (2017), dan tari Ngumang Malewa versi SMP (2017). Kaharuddin Dea Imok dalam menciptakan tari Kemang Pasiki diilhami dari lingkungan masyarakat Sumbawa, khususnya masyarakat Alas seperti bagaimana aktivitas sehari-hari perempuan Sumbawa, dari sisi keterampilannya seperti menjahit, menenun, menumbuk padi dan berhias diri.

Tari Kemang Pasiki ditarikan oleh 6 penari perempuan. Makna dari angka 6 ini bagi Kaharuddin Dea Imok diartikan sebagai 6 sifat perempuan Sumbawa yaitu tegas, lembut, sopan, cerdas, berani dan rendah hati. Terbentuknya 6 sifat ini dikerenakan dari lingkungan budaya Sumbawa yang masih berpegang erat dengan aturan-aturan yang ada, seperti adab-adab yang harus dijaga dan budaya masa lalu yang diaplikasikan dalam kehidupan sehari-hari. Dari latar belakang tersebut Kaharuddin Dea Imok menciptakan tari Kemang Pasiki yang mengekspresikan dari 6 sifat perempuan Sumbawa (Kaharuddin Dea Imok, wawancara 14 februari 2018).

Kaharuddin Dea Imok dalam menciptakan karya baru menggunakan gerak-gerak dasar tari Sumbawa yang ada, kemudian dikembangkan menjadi karya baru. Gerak bajempit, ngiting, tanak sorong, ninting sereh, beselunte, yang merupakan gerak dasar dari tari Sumbawa, lalu dikembangkan dengan gerak keseharian seperti menjahit, menenun, menumbuk padi dan berhias diri, Sehingga ditemukanlah gerak-gerak yang baru.

Rias dan busana tari Kemang Pasiki menggunakan rias cantik dengan busana baju adat khas Sumbawa yaitu lamung pene (baju) berwarna pink muda, dan kre (rok) berwarna hijau motif bunga dan di pundak sebelah kiri dihiasi dengan kidas angin yang berwarna kuning berbentuk segitiga, kemudian menyambung dengan punyung lakang (konde), kemang kanentek, klaru (gelang), dua kemang sumping plastik (kembang plastik), bangkat troe (anting), 
tonang baranak (kalung) dan pendeng (ikat pinggang). Busana tari Kemang pasiki tidak berpatokan kepada satu warna lamung pene (baju khas Sumbawa) seperti asesoris lainnya yang digunakan dalam tari Kemang Pasiki.

Tari Kemang Pasiki menggunakan iringan musik tradisional khas Sumbawa yang menggunakan instrumen yang terdiri dari 3 rebana rea (rebana besar), 1 buah pelompong (alat musik yang tersusun dari 4 kayu), 2 genang (gendang), 1 serunai (alat musik tiup yang terbuat dari daun Lontar), dan 1 buah gong. Aplikasi musik dalam tari Kemang Pasiki sangat beragam yang didukung dengan permainan musik yang dapat memunculkan berbagai macam suasana seperti suasana tegas, tenang dan gembira. Umumnya tari Kemang Pasiki selalu menggunakan musik live atau langsung dalam setiap pementasan.

Tahun 2016 tari Kemang Pasiki diminta oleh Dinas Kebudayaan Sumbawa agar bisa berpatisipasi dalam acara Festival Pagelaran Seni Pelajar SMP se-Provinsi NTB. Tari Kemang Pasiki mewakili Kecamatan Alas sekaligus sanggar Kemban Alas yang diketuai sendiri oleh Kaharuddin Dea Imok. Pemilihan tari Kemang Pasiki ini dikarenakan tari Kemang Pasiki dianggap masih lekat dengan budaya yang ada di Sumbawa. Hal yang juga menarik dari tari Kemang Pasiki yaitu dalam penyajiannya menggunakan penari dan pemusik yang masih duduk di bangku SMP. Keunikan lain dari tari Kemang Pasiki yaitu adanya sebagian gerak lambaian tangan pada tari Redat dan tari Zapin yang digunakan kedalam tari Kemang Pasiki. Memasukkannya unsur-unsur tari Redat dan tari Zapin mampu memunculkan nuansa keislaman dalam tari Kemang Pasiki (Kaharuddin Dea Imok, wawancara 14 februari 2018).

Kaharuddin Dea Imok merupakan seniman yang cukup terkenal di Alas kecamatan Alas Sumbawa. Terbukti dengan beberapa karya tari yang diciptakan cukup terkenal dalam masyarakat Alas dan dipentaskan diberbagai event atau acara, baik di desa Alas maupun di luar kota. Kaharuddin merupakan seniman tari sekaligus penata musik tradisional Sumbawa yang mempelajari tari maupun musik secara otodidak. Ada diantaranya karya Kaharuddin Dea Imok yang dipentaskan dalam berbagai acara seperti tari Lisu dan tari Sentek Kemang. Tari Lisu diciptakan oleh Kaharuddin Dea Imok yang terinspirasi dari budaya masyarakat Sumbawa pada saat berpacaran di zaman dahulu, yang penggambaran perasaan cinta laki-laki kepada perempuan dalam bentuk rebalas lawas (berbalas pantun). Perlu diketahui pada zaman dahulu laki- laki dan perempuan untuk mengungkapkan perasaan cintanya dengan cara Rebalas lawas (berbalas pantun).

Tari Sentek Kemang diciptakan pada tahun 2002 yang diangkat dari cerita lingkungan masyarakat Sumbawa pada zaman dahulu. Tari Sentek Kemang ini mengangkat tentang kebudayan Sumbawa yang masih menggunakan tradisi perjodohan antara keluarga satu dengan keluarga lainnya. Pertemuan kedua mempelai pada saat melakukan perkenalan dilakukan pada saat pertemuan keluarga dengan posisi kedua mempelai belum pernah bertemu sama sekali.

Seperti halnya tari Kemang Pasiki yang telah disebutkan diatas, karya 
Kaharuddin Dea Imok bisa dikatakan berpedoman pada Budaya Sumbawa. Ketertarikan penulis mengambil objek Tari Kemang Pasiki yaitu terkait dengan latar budaya dan kepribadian perempuan Sumbawa dalam kehidupan sehari-hari. Tari Kemang Pasiki tidak hanya berfungsi sebagai hiburan saja tetapi juga dijadikan pembelajaran di sanggar Kemban Alas yang berada di Alas Sumbawa. Selain itu, eksistensi tari Kemang Pasiki cukup terkenal di Alas seperti ditampilkan pada acara penikahan, dan pawai budaya ataupun acara pemerintah, Menurut Kaharuddin Dea Imok tari Kemang Pasiki belum pernah ada yang meneliti (Kaharuddin Dea Imok, wawancara 14 Februari 2018).

\section{KREATIVITAS KAHARUDDIN DEA IMOK DALAM KARYA TARI KEMANG PASIKI DENGAN PENDEKATAN 4P}

\section{Pribadi (person)}

Pribadi atau person merupakan peran penting yang mampu menumbuhkan ide kreativitas dalam diri sendiri atau perseorangan, karna melalui pribadi mampu menumbuhkan ide kreatif yang baru dengan adanya dukungan dari lingkungan sekitar. Pernyataan ini di perkuat oleh HulbacK dalam Munandar bahwa creativity actrition is an imposing of one's own uhole personality on the environment in a unique and characterristic way adapun terjemahannya sebagai berikut tindakan kreatif muncul darikeunikan keseluruhan kepribadian dalam interaksi dengan lingkungannya (Munandar, 1999: 26).

Kreativitas sangat erat kaitannya dengan gaya perseorangan, karena proses penciptaan karya seni merupakan perpaduan faktor internal dan eksternal (Bahari, 2008:24). Kaharuddin Dea Imok adalah seseorang yang terlahir dari keluarga yang sederhana, dilihat dari pribadinya Kaharuddin adalah seorang yang gigih, ceria, tekun, ramah dan tidak gampang berputus asa bila ingin mendapatkan sesuatu. Kaharuddin dikenal sebagai pribadi yang senang melihat lingkungan yang ada disekitarnya, seperti kebudayaan ataupun kebiasaan yang sering dilakukan oleh masyarakat Sumbawa (Kaharuddin Dea Imok, wawancara 16 November 2018).

Kaharuddin Dea Imok adalah koreografer yang memiliki pengalaman yang cukup dalam berkesenian seperti menciptakan sebuah karya tari. Dari kecil Kaharuddin Dea Imok merupakan pribadi yang selalu ingin membuat sesuatu yang baru dengan menceritakan kebudayaan yang ada di Sumbawa salah satunya yaitu tari Kemang Pasiki. Dari kegigihanya yang kuat Kaharuddin Dea Imok berusaha untuk menciptakan sebuah karya yang menceritakan kebiasaan perempuan Sumbawa dengan menggunakan gerakangerakan dasar tari Sumbawa seperti melihat aktivitas-aktivitas yang sering dilakukan oleh perempuan Sumbawa.

Totalitas yang ditunjukan oleh Kaharuddin Dea Imok dalam tari Kemang pasiki yaitu dengan menciptakan karya tari baru, seperti menggabungkan tari Redat dan tari Zapin yang dimasukkan kedalam tari Kemang Pasiki. Tari Redat dan tari Zapin merupakan tari yang berbeda tetapi di dalam tari Kemang Pasiki Kaharuddin Dea Imok mencoba untuk menggabungkan kedua tari yang berbeda tersebut ke dalam satu karya tari, sehingga 
terciptalah karya tari yang berjudul Kemang Pasiki. Berkat dari ketekunan maupun kemauan yang kuat Kaharuddin mampu menarik lingkungan sekitar untuk bisa menjadi pusat perhatian dari masyarakat.

\section{Pendorong (press)}

Pendekatan terhadap kreativitas menekankan faktor pendorong (press) atau dorongan, baik dorongan internal (dari diri sendiri) maupun dorongan eksternal dari lingkungan sosial dan psikolog (Munandar, 1999: 28).

\section{Faktor internal}

Faktor internal yang membuat Kaharuddin Dea Imok sebagai seorang Koreografer yaitu mempunyai keinginan besar untuk bisa melestarikan dan memperkenalkan budaya Sumbawa ke masyarakat luar. Ciptaan dari Kaharuddin Dea Imok salah satunya yaitu tari Kemang Pasiki. Kaharuddin Dea Imok ingin menunjukan bagaimana kebiasaan perempuan Sumbawa pada zaman dahulu yang mempunyai banyak keterampilan. Bagi Kaharuddin Dea Imok sebagai seorang seniman tidak pernah takut menciptakan sesuatu yang baru, karna dengan ciptaan barunya tersebut Kaharuddin Dea Imok bisa menunjukan eksistensi dirinya sebagai seorang koreografer. Inilah faktor internal yang mendorong Kaharuddin Dea Imok menjadi lebih baik karna keinginan itu tumbuh dari dirinya sendiri, dengan keihlasan yang dimilikinya untuk selalu mengembangkan adat istiadat budaya Sumbawa.

Kaharuddin Dea Imok bukanlah orang yang berasal dari seniman yang terkenal melainkan seorang seniman otodidak yang bergelar sarjana hukum. Kaharuddin Dea Imok tidak mau berbangga diri atas hasil yang di capai seperti kepercayaan yang didapatkannya karena Kaharuddin Dea Imok sadar tidak selamanya yang direncanakan berjalan sesuai dengan harapan. Bagaimanapun Kaharuddin Dea Imok berusaha ikhlas dalam membuat sesuatu yang baru dan kreatif, karna berkesenian bukan menunjukan siapa yang lebih baik melainkan bagaimana caranya kita bisa melestarikan kebudayan yang ada. Itulah kemenangan yang ingin di dapatkan oleh Kaharuddin Dea Imok (Kaharuddin dea Imok, wawancara 16 November 2018).

\section{Faktor Eksternal}

Selain faktor internal yang mampu mewujudkan kemauan dalam diri sendiri supaya mendapatkan hasil yang maksimal. Ada pula faktor eksternal yang mampu mempengaruhi Kaharuddin Dea Imok. Faktor eksternal tersebut didukung oleh lingkungan masyarakat dan dukungan dari pemerintah setempat yang mempercayai Kaharuddin Dea Imok dalam menciptakan sebuah karya tari. Pemerintah Dinas Kebudayaan NTB meminta Kaharuddin Dea Imok untuk mewakili Kecamatan Alas tampil di acara Festival Pergelaran Seni SMP se- Provinsi NTB. Kaharuddin Dea Imok diminta untuk membuat karya tari yang masih berhubungan dengan kebudayaan yang ada di Sumbawa. Maka disusunlah oleh Kaharuddin Dea Imok tari Kemang Pasiki.

Pendorong Eksternal luar lainnya adalah dari masyarakat khususnya lingkungan masyarakat Alas. Masyarakat Alas mempercayai Kaharuddin Dea Imok untuk mengajari dan memasukan anak 
mereka ke sanggar Kemban Alas yang diketuai sendiri oleh Kaharuddin Dea Imok. Saat itu anggota sanggar Kemban Alas mencapai 400 orang anak, karna semakin berkembangnya sanggar Kemban Alas, sehingga memicu Kaharuddin Dea Imok untuk menambah materi tari. Alasan Kaharuddin Dea Imok menambah materi tari karena pada saat itu materi yang diajarkan di Sanggar Kemban Alas masih dianggap kurang, jadi Permintaan dari masyarakat inilah yang mendorong Kaharuddin Dea Imok untuk lebih menambah materi di sanggar Kemban Alas yaitu tari Kemang Pasiki. Bukan hanya materi dalam seni tari saja tetapi Kaharuddin memperkenalkan musik tradisional Sumbawa maupun tari-tari yang diciptakannya seperti tari kemang Pasiki. (Kaharudin Dea Imok, wawancara 16 November 2018).

Di samping itu adanya permintaan dari SD yang ada di Alas yang mempercayai Kaharuddin Dea Imok untuk mengajari karya tari, seperti anak-anak sekolah yang berkebutuhan khusus yang mempunyai permintaan untuk membuat suatu karya tari yang mudah di mengerti oleh anak-anak yang berkebutuhan khusus. Dari Permintaan tersebut memacu Kaharuddin Dea Imok untuk menciptakan karya baru yang sesuai dengan anak Sekolah Dasar SLB Negri 2 Sumbawa. Tari Kemang Pasiki inilah yang diajarkan ke anak Sekolah Dasar SLB Negri 2 Sumbawa yang gerakannya menyesuaikan dari kemampuan anak berkebutuhan khusus. Empat tahun sudah Kaharuddin Dea Imok menjalin kerja sama dengan perangkat sekolah SLB karna di setiap kegiatan seni selalu ada permintaan untuk membuat karya seni, dan disinilah membuat Kaharuddin Dea Imok harus lebih kreatif dan bekerja keras agar bisa mendapatkan hasil yang maksimal. Adapun acara seni lainnya yang selalu di adakan oleh pemerintah di Kabupaten maupun Provinsi yang selalu bekerja sama dengan Kaharuddin Dea Imok.

Bukan bicara tentang tari saja tetapi Kaharuddin Dea Imok dipercayai untuk mengajarkan musik tradisional Sumbawa kepada anak didiknya di sanggar Kemban Alas. Dari sinilah banyak terjalin kerja sama antara pemerintah dan masyarakat sekitar. Hal ini sesuai dengan yang disampaikan Alo Liliweri dalam bukunya bahwa Komunikasi merupakan satu-satunya cara atau jalan yang mana mereka membentuk kebersamaan maka terciptalah tujuan bersama, aspirasi, pengetahuan. Komunikasi menjadi sangat penting dalam membentuk sebuah kebersamaan (Liliweri, 2002:197).

Kaharuddin Dea Imok sangatlah memegang prinsip karna bila dijalankan, dengan giat dan gigih semuanya akan tercapai. Adanya dukungan dari lingkungan sangatlah berpengaruh bagi pribadi Kaharuddin Dea Imok karna tidak ada orang yang sukses tampa orang yang selalu berada di belakangnya. Kaharuddin Dea Imok selalu bernyukur atas apa yang didapatkannya, dengan kepercayaan dari masyarakat, pemerintah maupun lingkungan lainnya. Umumnya Kaharuddin dipercayai untuk menjadi panitia ataupun ketua di setiap event acara seni seperti pawai budaya, pendamping teknis lomba membuat male' (hiasan maulid nabi), Samawa basarunai, majalah dinding kreativitas barang bekas tingkat SLTP/ SMA se-Kabupaten Sumbawa, Guru 
terinovatif/kreatif tahun 2018 dan lain sebagainya.

Seperti dikatakan diatas Kaharuddin Dea Imok dalam menciptakan tari Kemang Pasiki mempunyai beberapa faktor pendorong dari luar seperti pemerintah, masyarakat maupun SD yang ada di Kecematan Alas. Dari situlah memicu Kaharuddin Dea Imok untuk menciptakan tari Kemang pasiki.

\section{Proses (process)}

Proses merupakan bagian yang sangat penting dalam menciptakan sebuah karya tari. Menurut Rhodes the term process applies to motivation perception, learning thinking, and communicaling (Rhodes 196:308). Istilah tersebut dapat diterjemahannya bahwa proses berlaku untuk persepsi motivasi, belajar, berfikir, dan berkomunikasi. Mengawali sebuah proses harus bisa melihat pengalaman-pengalaman pribadi atas apa yang di lihat dengan cara berfikir, dan belajar dari pengalaman yang pernah dilalui, karena dalam melihat tersebut munculah sebuah ide-ide baru yang kreatif. hal ini sesuai dengan diungkapkan oleh Soedarsono bahwa :

Pada dasarnya manusia mencari pengalaman kreatif dan estetis, karena dari pengalaman tersebut manusia dapat memperkaya pengalaman pada dirinya. Proses kreatif dapat tibul dari apa yang kita lihat sehingga dalam berproses mampu memunculkan ide kreatif Koreografer. Melalui pengalamanpengalaman kreatif dan estetis, koreografer dapat menjadi seorang pribadi yang mampu menciptakan hal baru melalui pengalaman hidupnya (Soedarsono: 178: 38).
Proses dalam menciptakan suatu karya sangatlah penting karena akan mempengaruhi kualitas karya yang akan diciptakan. Proses dibutuhkan keyakinan, keseriusan bila ingin mendapatkan hasil yang maksimal. Hasil yang maksimal akan didapatkan bila koreografer, penari maupun pemusik bisa berkerja sama secara baik.

Pada setiap proses koreografer, penari dan musik tidak selamanya berjalan dengan lancar sesuai dengan harapan sehingga pada saat menciptakan hal yang baru harus membutuhkan pemecahan yang baik untuk menemukan jalan keluar, maka dalam berproses musik dan tari harus bisa berkesinambungan dan bekerja sama agar mendapatkan hasil yang maksimal.

Proses penciptaan karya tari Kemang Pasiki berawal dari mengamati perempuan Sumbawa dalam melakukan pekerjaan sehari-hari, seperti memasak, mencuci baju, menenun, berhias diri dan lain sebagainnya. Pada proses inilah Kaharuddin Dea Imok menciptakan karya tari dengan menggunakan gerakan-gerakan yang terinspirasi dari keterampilan perempuan Sumbawa kemudian di tuangkan ke dalam tari Kemang Pasiki.

Penciptaan tari Kemang pasiki melalui beberapa tahapan yaitu Eksplorasi, Improvisasi dan Komposisi. Hal ini sesuai dengan pendapat Alma M. Hawkins yang diterjemahkan oleh Y. Sumandiyo Hadi dalam buku mencipta lewat tari menyatakan bahwa:

Respon kreatif dapat dicapai melalui proses-proses eksplorasi dan imvrovisasi serta melalui masalah-masalah komposisi yang memberikan satu kesempatan bagi penari untuk berfikir, merasakan, 
mengimajinasikan serta menciptakan (Hadi, 1990: 49-50).

Proses Eksplorasi, Improvisasi, dan komposisi. Berangkat dari proses awal penggarapan penciptaan dilakukan Eksplorasi terlebih dahulu guna memperoleh sesuatu yang baru.

\section{Eksplorasi}

Eksplorasi adalah langkah awal yang di lakukan oleh koreografer untuk menciptakan suatu karya tari yaitu berfikir, berimajinasi, merasakan dan meresponsikan (Soedarsono, 1978:40). Eksplorasi yang dilakukan oleh Kaharuddin Dea Imok dalam menciptakan tari Kemang Pasiki dimana ingin mengangkat bagaimana keterampilan yang dimiliki oleh perempuan Sumbawa. Kaharuddin Dea Imok melakukan pencaharian ide dengan lebih berfikir bagaimana konsep yang akan di tuangkan kedalam tari Kemang Pasiki seperti menggunakan gerak-gerak dasar yang sudah ada sebelumnya, yaitu bajempit, bagiting, basalunte, ngijik, nengke, linting sere dan lain sebagainya, lalu di gabungkan dengan gerakan keseharian yang terispirasi dari aktivitas-aktivitas yang dilakukan oleh perempuan Sumbawa seperti menjahit, menenun, dan berhias diri. Kaharuddin Dea Imok mempunyai ide agar tari Kemang Pasiki terlihat lebih menarik dengan tari sebelumnya yang pernah diciptakan, yaitu memasukkan gerak tari Redat dan tari Zapin ke dalam tari Kemang Pasiki. Kedua tarian ini merupakan tari yang berbeda namun mempunyai persamaan yaitu mengandung unsur keislaman.
Pemilihan tari Redat dan Zapin kedalam Kemang Pasiki karena adanya pengaruh islam dalam adat istiadat Sumbawa. Sebagian besar masyarakat Sumbawa menganut agama islam oleh karena itu Kaharudin Dea Imok ingin membuat sebuah tari yang bernafaskan islam namun tidak meninggalkan unsur tradisi masyarakat Sumbawa itu sendiri. Pernyataan ini di perkuat oleh Aries Zulkarnain dalam bukunya yang berjudul Karakteristik Kepemimpinan yang menyatakan bahwa dalam seni musik, dominan kesenian yang bernafaskan Islam seperti Ratib dan Zapin (Zulkarnain 2008:28).

Dalam hal ini Kaharuddin Dea Imok juga mencari pengetahuan mengenai bagaimana watak perempuan Sumbawa pada zaman dahulu, Kaharuddin Dea Imok mencari referensi-referensi buku yang sudah ada dan menanyakan kepada pemangku adat maupun masyarakat yang lebih memahami mengenai hal keterampilan maupun pekerjaan sehari-hari sebagai perempuan Sumbawa. pandangan watak perempuan Sumbawa yang didapatkan oleh Kaharuddin Dea Imok yaitu tegas, lembut, sopan, cerdas, berani dan rendah hati watak tersebut merupakan pandangan ideal Kaharuddin Dea Imok terhadap perempuan Sumbawa.

\section{Improvisasi}

Improvisasi adalah langkah selanjutnya yang dilakukan oleh koreaografer dalam menciptakan tari Kemang Pasiki. Improvisasi yang dikatakan oleh Soedarsono, bahwa : 
Improvisasi sering dikatakan sebagai spontanitas dalam melakukan gerak. Namun jika digunakan atau diterapkan secara tepat dapat menjadi salah satu cara yang berharga untuk meningkatkan kemampuan dan pengembangan sikap kreatif dalam menciptakan gerak (Soedarsono, 1978: 40).

Dalam proses penciptaan karya tari Kemang Pasiki Kaharuddin Dea Imok menggunakan gerak yang sudah ada sebelumnya seperti gerak dasar tari Sumbawa, gerak ini dilakukan dalam perpindahan pola lantai seperti gerak ngijik, ninting sere, dan bejempit, kemudian menggunakan gerak-gerak yang berangkat dari gerak keseharian yang terinspirasi dari aktivitas perempuan Sumbawa seperti menjahit, menenun, menumbuk padi dan berhias diri. Gerakan ini lebih menggunakan permainan level dan volume, contohnya gerakan menjahit pada tari Kemang Pasiki dengan menggunakan level rendah dengan volume lebih besar yang melebihi gerakan menjahit seperti biasanya.

Selanjutnya menggunakan tari Redat dan tari Zapin yang gerakannya lebih energik dan lebih semangat. Gerak tari Redat dan tari Zapin menggunakan permainan tangan yang terlihat lebih tegas pada saat menarikannya. Barulah Kaharuddin Dea Imok mencoba mengeksplorasi dan memadukan gerakan yang sudah ada tersebut dengan lebih melakukan permainan dinamika gerak. Gerak yang dimasukkan kedalam tari Kemang Pasiki seperti, contoh cepat lambatnya yang digunakan dalam tari Kemang Pasiki yang disesuaikan dengan gerakan yang ditarikan, sehingga terciptalah gerak baru sesuai dengan keinginan dari Kaharuddin Dea Imok.

\section{Komposisi}

Komposisi adalah tahap selanjutnya dilakukkan oleh koreografer dalam menciptakan sebuah karya tari, Melalui tahap eksplorasi dan improvisasi. Dari proses inilah muncul bentuk baru yaitu karya tari yang menggunakan gerakan dasar dengan penggabungan gerakan tari Redat dan tari Zapin. Komposisi ini bisa disebut dengan ranggakaian proses pada saat membuat sebuah karya tari. Kaharuddin Dea Imok menyusun gerakan berdasarkan eksplorasi dan improvisasi. Proses eksplorasi dan improvisasi Kaharudin mengolah gerakan menjadi sebuah gerak tari. Dengan penyusunan gerak tari yang sudah dibuat. Dari situlah Kaharuddin Dea Imok melakukan proses latihan karena dalam melakukan latihan penari dengan mudah menghafal pola lantai dan menghasilkan kekompakan satu sama lain.

Selain penari Kaharudin Dea Imok juga melatih para pemusik. Musik tari Kemang Pasiki diciptakan sendiri oleh Kaharuddin Dea Imok, musik tari yang di gunakan dalam tari Kemang Pasiki yaitu musik tradisional Sumbawa dengan menggunakan nada yang lebih beragam. Kaharuddin Dea Imok selalu memberikan pengajaran keapada pemusik semaksimal mungkin sehingga bisa sesuai diharapkan. Dalam penciptaan Karya tari Kaharuddin Dea Imok lebih menggunakan gerakan yang kreatif seperti gerak tari Redat dan gerak tari Zapin agar terlihat lebih menarik dan tidak menimbulkan kebosanan bagi para penonton. Gerak- gerak tersebut 
dikembangkan dan dikemas agar terlihat tersusun menarik dengan menggabungkan musik yang diciptakan sendiri oleh Kaharuddin Dea Imok antara musik Redat dan musik Zapin.

Kaharuddin Dea Imok dalam menyusun tari selalu dilihat dari bagian pertama sampai akhir. Proses karya tari yang akan ditarikan seperti melihat bagian awal, seperti 6 penari perempuan tari Kemang Pasiki yang membelakangi pangggung yang mencerikan tentang perempuan Sumbawa zaman dahulu lebih tertutup. Bagian kedua yaitu adegan penari dengan gerakan melambaikan tangan yang terinspirasi dari aktivitas sehari-hari seorang perempuan seperti bermain, menjahit, berhias diri menyuci, merajut dan lain sebagainya. Bagian ketiga yaitu melakukan gerakan Redat dan Zapin yang terinspirasi dari mayoritas sorang muslim di Sumbawa (Kaharuddin Dea Imok, wawancara 16 November 2018).

\section{Produk (product)}

Produk adalah hasil akhir yang akan dilakukan oleh Kaharuddin Dea Imok dalam menciptakan suatu karya tari Kemang Pasiki, setelah dilakukannya eskplorasi, impropisasi, dan komposisi. Produk yang dihasilkan yaitu tari Kemang Pasiki. Tari Kemang Pasiki menjadi sebuah produk yang saat ini cukup dikenal dan diminati oleh masyarakat Sumbawa khususnya desa Alas. Terbukti tari Kemang Pasiki yang sering terlibat dalam setiap pementasan maupun acara yang di lingkungan masyarakat khususnya desa Alas Kecamatan Alas. Keterlibatan pementasan dalam berbagai acara seperti, menjadi tari hiburan di setiap acara festival maupun acara seni lainnya, acara khitanan, hajatan, penikahan dan lain sebagainya. Adapun yang lainnya tari Kemang Pasiki menjadikan sebagai bahan ajar di Sanggar Kemban Alas ataupun di SMAN 1 Alas yang yang di pelajari dari generasi ke generasi.

Kaharuddin Dea Imok adalah salah satu koreografer yang mempunyai kepekaan terhadap fenomena-fenomena yang sedang berkembang dilingkungan masyarakat. Tari Kemang Pasiki merupakan salah satu produk yang dilihat dari lingkungan masyarakat Sumbawa, dari fenomenafenomena yang terjadi di lingkungan masyarakat seperti kebiasaan yang selalu dilakukan, ataupun adat budaya yang masih di terapkan sampai saat ini. Tidak hanya dari lingkungan masyarakat saja tetapi Kaharudin Dea Imok juga melihat dari pengalaman pribadinya sendiri yang sudah pernah dilalui seperti pengalaman bahwa Kaharuddin Dea Imok pernah hidup dalam budaya masyarakat Sumbawa yang masih berpegang dengan adat istiadat zaman dulu, adapun pengalaman dia berkarya, menjadi seorang penari maupun menjadi seorang penata musik.

Sejak saat itulah produk kreatif dari tari Kemang Pasiki yang diciptakan oleh Kaharuddin Dea Imok menjadi salah satu karyanya yang cukup dikenal dan diminati dilingkungan Masyarakat Alas maupun sekitasnya, terbukti dengan selalu adanya permintaan untuk tampil di berbagai acara seperti perlombaan Smp se propinsi NTB yang di adakan di Mataram. Adapun acara lainnya di lingkungan masyarakat yaitu penikahan, penyambutan tamu dan di acara penting lainnya. 
Dari pengalamannya Kaharuddin Dea Imok dalam setiap karya yang pernah diciptakannya dianggap berkualitas oleh masyarakat Alas. Terbukti dengan banyaknya permintaan dari masyarakat untuk selalu menghadiri acara seni maupun acara lainnya. Kaharuddin Dea Imok juga dinilai sebagai koreografer yang konsisten, dan yang bisa beradaptasi dengan semua kalangan seperti siswa yang berkebutuhan khusus. Kaharuddin Dea Imok selalu bisa memfasilitasi kebutuhan mereka tentang tari, disinilah nilai lebih yang didapatkan oleh Kaharuddin Dea Imok sebagi salah satu koreografer yang berkualiatas di tengah masyarakat Alas, karna Kaharuddin Dea Imok selalu memberikan mereka pembekalan ilmu tentang kebudayaan Sumbawa dalam menciptakan suatu karya yang masih berpegang dengan adat istiadat kebudayaan Sumbawa (Tini, wawancara 16 November 2018).

Berdasarkan penjelasan diatas kreativitas menurut Rhodes mempunyai 4 dimensi yaitu pribadi, pendorong, proses dan produk. Kaharuddin Dea Imok merupakan seorang Seniman dari Alas Kecamatan Alas Kabupaten Sumbawa. Banyaknya karya yang telah diciptakan oleh Kaharuddin Dea Imok ada 8 karya dan salah satunya tari Kemang Pasiki. Tari Kemang Pasiki ini diciptakan oleh Kaharuddin Dea Imok pada tahun tahun 2016. Tari ini diciptakan untuk keperluan lomba Festival Pergelaran Seni Pelajar SMP se- Provinsi NTB, yang didorong oleh pemerintah Dinas Kebudayaan NTB. Proses penciptaan tari Kemang Pasiki oleh Kaharuddin Dea Imok dengan melakukan eksplorasi, improvisasi dan komposisi.
Berdasarkan Penciptaan tari Kemang Pasiki ini Kaharuddin Dea Imok sudah melalui beberapa proses garap yang tidak terlepas dari unsur-unsur yang ada, sehingga terciptalah tari Kemang Pasiki yang dikenal oleh masyarakat Alas dan Sekitarnya.

\section{PENUTUP}

Tari Kemang Pasiki merupakan tarian dari daerah Alas Kecamatan Alas Kabupaten Sumbawa, yang diciptakan oleh Kaharuddin Dea Imok pada tahun 2016, yang mengungkapkan kelembutan dan keterampilan perempuan Sumbawa dalam melakukan aktivitas sehari-hari. Tari Kemang Pasiki diciptakan untuk keperluan lomba Festival Pergelaran Seni Pelajar SMP se- Provinsi NTB, yang didorong oleh pemerintah Dinas Kebudayaan NTB.

Bentuk Tari Kemang Pasiki memiliki strukturyang di dalamnya terdapat elemenelemen tari yaitu gerak, pola lantai, musik, rias busana, dan tempat pertunjukan. Gerak dalam tari Kemang Pasiki menggunakan gerakan dasar tari Sumbawa, dengan gerak keseharian perempuan Sumbawa yang terinspirasi dari aktivitas sehari-hari, kemudian digabungkan dengan gerat tari Redat dan tari Zapin. Pola lantai dalam tari Kemang Pasiki menggunakan pola lantai khusus seperti pola lantai lurus, segitiga, diagonal dan membentuk huruf V. Kaharuddin Dea Imok lebih memilih pola lantai yang lebih kreatif seperti banyaknya keragaman transisi dalam setiap perpindahan pola lantai. Musik di dalam tari Kemang Pasiki lebih menggunakan alat musik tradisional Sumbawa yaitu gong, genang, rebana, pelompong, santong srek, kul-kul, dan saruai yang mampu menimbulkan suasana dan 
tempo dalam setiap transisi. Sedangkan rias busana dari tari Kemang Pasiki menggunakan busana khas Sumbawa seperti lamung pene, kre, lakang, kidas angina dan lain sebagainya, yang didukung dengan menggunakan riasan cantik yang sesuai dengan tari Kemang Pasiki. Elemen yang terakhir yanti tempat pertunjukan yang digunakan dalam tari Kemang Pasiki tidak mempunyai ketentuan mutlak karena tempat pertunjukan yang digunakan disesuaikan dengan kondisi yang sudah disediakan. Elemen-elemen tersebut menjadi satu kesatuan dan saling terkait dalam sebuah karya tari Kemang Pasiki.

Kreativitas dalam tari Kemang Pasiki tidak hanya dapat dilihat dari perwuudan gerak perempuan Sumbawa seperti gerak dasar Sumbawa, gerak tari Redat dan tari Zapin, dan gerak keterampilan, yang menggambarkan watak perempuan Sumbawa yaitu tegas, lembut, sopan, cerdas, berani, dan rendah hati. Tetapi, juga dilihat dari gerak, pola lantai, music, dan rias busana yang terkait dan saling bergayutan menjadi satu kesatuan dalam tari Kemang Pasiki. Proses penciptaan Kaharuddin Dea Imok dalam tari Kemang Pasiki dapat dilihat dari hasil eksplorasi, yang di dalamnya terdapat berfikir, imajinasi, merasakan dan merespon, kemudian melakukan improvisasi dan komposisi.

Tari Kemang Pasiki adalah karya tari yang menunjukkan Kaharuddin Dea Imok adalah seorang yang kreatif, dan melalui eksistensi dari tari Kemang Pasiki, Kaharuddin Dea Imok dapat dikenal oleh masyarakat Alas dan sekitarnya.

\section{DAFTAR PUSTAKA}

Bahari, Nooryan. 2008. Kritik Seni: Wacana, Apresiasi dan Kreasi. Yogyakarta: Pustaka Pelajar,

Hadi, Sumandiyo.Y. 2003 . Aspek-Aspek Dasar Koreografi Kelompok. Yogyakarta: Lembaga Kajian Pendidikan Humaniora Indonesia. . 2017. Bentuk - Tehnik - Isi. Yogyakarta: Cipta Media Bekerja Sama Dengan Rintisan Akademik Komonitas Negri Seni Dan Budaya.

Hawkins, Alma. M . 1990. Mencipta Lewat Tari. Diindonesiakan oleh Y. Sumandiyo Hadi. Yogyakarta: Institus Seni Indonesia.

Hapsari, Fani Dwi. 2014. Kreativitas Boby Ari Setyawan Dalam Karya Tari Hanacaraka. Skripsi jurusan tari.

Kalimati, Wahyu Sunan. 2005. Pilar-Piilar Budaya Sumbawa. Sumbawa Barat: Dinas Kebudayaan Dan Pariwisata.

Langer, Suzanne K. 1988. Problematika Seni. Diindonesiakan oleh $\mathrm{fx}$. Widaryanto. Bandung: Akademi Seni Tari Indonesia.

Liliweri, Alo. 2002. Dasar-Dasar Komunikasi Antar budaya. Yogyakarta: Pustaka Pelajar. 
Matja.Lalu. 2011. Sumbawa Pada Masa Dulu (Suatu Tinjauann Sejarah). Sumbawa Besar: Samratulangi.

Munandar, Utami. 2002. Kreativitas dan Keberbakatan strategi mewujudkan potensi kreatif dan bakat. Jakarta: Gramedia Pustaka Utama.

Nororduyn, J. 2007. Sejarah Sumbawa. Yogyakarta: Riset Informasi dan Arsip Kenegaraan.

Putra, Puradhi Mahatva Yusanto. 2017. Kreativitas Bambang Irawan dalam Karya Tari Lawung Kasenopaten. Skripsi Jurusan Tari.

Rhodes, Mel. 1961. An Analysis of Creativity. PHI Delta Kappa Internasional.

Saputri, Indah ayu. 2018. Koreografi A Smarasih Karya Umiyati Sri Warsin. Skripsi Jurusan Tari

Sugianto. 2014. Metode Penelitian Kualitatif Kuantitatif Dan $R$ \& $D$. Bandung: ALFABETA.

Soedarsono. 1978. Pengantar Pengetahuan dan Komposisi Tari. Yogyakarta: Akademi Seni Tari Indonesia,

Tasman, A. 2008. Analisa gerak dan Karakter. Surakarta: ISI Press.
Wahyuni, Sri. 2017. Kreativitas Surdianah Dalam Penciptaan Tari Ser Meni' Kuning Pada Sanggar Sareng Nyer Di Kecamatan Taliwang Kabupaten Sumbawa Barat. Skripsi Jurusan tari.

Widyastutieningrum, Sri Rochana. 2011. Sejarah Tari Gambyong: Seni Rakyat Menuju Istana. Surakarta: ISI Press.

Yusuf, Jafar. M . dkk. 2016. Pasanotang Tananang Boat Iwet Mate Telas Tau Samawa. Yogyakarta: Lembaga Adat Tana Samawa (LATS) Ano Rawi.

Zulkarnain, Aries. 2008. Karakteristik Kepemimpinan Dalam Adat Dan Rappang Tana Samawa. Lembaga Adat Tana Samawa, Sumbawa Besar.

\section{NARASUMBER}

1. Kaharuddin Dea Imok (58 tahun), narasumber utama ketua atau pembangun sanggar Kemban Alas. Alas, Sumbawa.

2. Agus Irawan syahmi (48 tahun), staff khusus Bupati Sumbawa Barat Bidang pendidikan dan Kebudaya. Taliwang, Sumbawa Barat.

3. Yunita Sari (23 tahun), penari. Alas, Sumbawa

4. Tini (27 tahun), guru kebutuhan Khusus SLB Negri 2 Sumbawa. Alas, Sumbawa. 